\title{
RIZICI ZLOUPOTREBE TRŽIŠNE MOĆI NA BERZAMA ELEKTRIČNE ENERGIJE
}

\section{Zoran Jeremić ${ }^{1}$, Tatjana Latas ${ }^{2}$}

${ }^{1}$ Univerzitet Singidunum, Beograd, Srbija

${ }^{2}$ Somborelektro, Sombor, Srbija

\begin{abstract}
Apstrakt:
Predmet istraživanja ovog rada je mogućnost zloupotrebe tržišne moći na berzama električne energije. Osnovna hipoteza je da berze električne energije treba da posluju po sličnim principima kao i finansijske i robne berze, ali da su one podložne većim ograničenjima za efikasan rad, kao i većim mogućnostima zloupotrebe tržišne pozicije učesnika u trgovanju. Cilj rada je da identifikuje i objasni te potencijalne zloupotrebe i da predloži načine na koji se one mogu umanjiti, kao što su: smanjenje koncentracije na tržištu, povećanje brzine reakcije tražnje na promenu cena, smanjenje zagušenja na prenosnoj mreži, povećanje prosečnog nivoa hedžinga i kontrola nadmetanja.
\end{abstract}

Ključne reči:

berze električne energije, tržišna moć, tržišne manipulacije.

\section{UVOD}

Liberalizacija i deregulacija tržišta električne energije ima za cilj da podstakne tehnološke inovacije i konkurentnost, ali i da ukine monopole i ojača konkurenciju na tržištu, koja treba da dovede do snižavanja cene električne energije. Da bi sprovela takvu politiku Evropska komisija podstiče osnivanje i rad berzi električne energije i procese spajanja tržišta. Berze električne energije posluju po istim principima po kojima posluju finansijske i robne berze, ali je umesto akcija, roba i robnih derivata predmet trgovanja na berzi električna energija. Mada se primenjuju isti berzanski principi trgovanje električnom energijom ipak ima i brojne specifičnosti koje je potrebno uvažiti i prilagoditi modelima i sistemima trgovanja. Predmet rada su upravo specifičnosti koje dovode do mogućnosti zloupotrebe tržišne moći na berzi.

Osnovna hipoteza rada je da se na berzama električne energije tržišna moć može zloupotrebiti i da stoga ovo tržište mora biti predmet dodatne pažnje i odgovarajuće regulative i nadzora. Manipulacije ne bi bilo u uslovima savršene konkurencije, gde bi postojalo obilje ponude i tražnje, kada bi se svaka generatorska kompanija koja traži više od MCP (market clearing price) i svaki potrošač koji nudi manje od MCP mogli zameniti, odnosno kada bi svi učesnici na tržištu bili „price takers“. Međutim, na tržištu električne energije ovakvo stanje je samo teorijski moguće, dok u praksi postoji niz anomalija koje onemogućavaju postojanje takozvanog efikasnog tržišta na kojem postoji veliki broj naloga ponude i tražnje, odnosno širina i dubina tržišta, gde nijedan pojedinačni učesnik ne može uticati na cenu. Kada se radi o razvijenim finansijskim berzama gotovo je nemoguće da pojedinačni učesnik manipuliše cenom, jer bi to zahtevalo posedovanje enormnih sredstava, a verovatnoća da će postići cilj trenutnog veštačkog povećanja ili smanjenja cene neke akcije je minimalna. Kod tržišta valuta (FOREX) je slična situacija zbog veličine tržišta, jer se kupovina i prodaja obavljaju 24 časa dnevno, a na globalnom tržištu postoji mnogo učesnika. Mada su ova tržišta standardizovana, sa brzim i efikasnim saldiranjima transakcija i bez problema u sigurnosti i protoku datih naloga i uplata, ipak u praksi postoje primeri gde je jedan moćni tržišni učesnik mogao 
uticati na kurs i cene. Tržište električne energije mnogo je podložnije mogućnostima tržišne manipulacije u odnosu na finansijske, robne berze i devizno tržište, jer je ono zahtevnije u pogledu predmeta trgovanja, brzine i volumena protoka predmeta trgovanja, kao i nekih drugih specifičnosti koje predstavljaju otežavajuće faktore za efikasno funkcionisanje berzi električne energije.

Tržišta električne energije su osetljiva na uticaj tržišne moći. Zbog varijabilne tražnje i zbog nemogućnosti skladištenja autputa, u određenim periodima su potrebni svi raspoloživi kapaciteti kako bi se zadovoljila trenutna tražnja. Iz ovog razloga tržišta električnom energijom su osetljivija na uticaj tržišne moći nego bilo koja druga tržišta. Smatra se da kompanija ima značajnu tržišnu moć, ukoliko ima veliki uticaj na količinu dobara kojima se trguje na jednom tržištu i na cene po kojima se prodaje. Cilj rada je da objasni mogućnosti zloupotrebe usled korišćenja tržišne moći i da predloži potrebne mere za sprečavanje i ublažavanje eventualnih zloupotreba tržišne pozicije učesnika u trgovanju na berzama električne energije.

\section{FUNKCIONISANJE BERZI ELEKTRIČNE ENERGIJE}

Berze električne energije funkcionišu u okviru tržišne zone koja obuhvata elektroenergetsku mrežu, koja se obično podudara sa regulacionim oblastima operatora prenosnog sistema (Stefanović, 2015). Za razliku od većine drugih tržišta, trgovina električnom energijom se ne može posmatrati samo na osnovu ponude i tražnje. Značajnu ulogu u toj trgovini igra interkonektivni kapacitet, koji postavlja ograničenja na tržištu električne energije određenog područja, pa i na samoj berzi, kao delu celokupnog tržišta električne energije. Naime, tokovi snage u električnoj mreži određuju obim maksimalne trgovine na tržištu. Oni nisu proizvoljni već su određeni matematičkim modelom mreže (Power flow), iz čega proizilazi da se svi zaključeni kupoprodajni ugovori (na berzi ili direktno), obavezno prijavljuju nacionalnom operatoru tržišta. Informacije o ugovorenim transakcijama se prosleđuju operatoru prenosnog sistema koji je zadužen za nadgledanje realizacije ugovorenih obaveza svih učesnika, i koji u slučaju odstupanja vrši balansiranje sistema u realnom vremenu. Stoga su svi učesnici na tržištu dužni da pošalju posebnu ponudu za svaki od 24 časa narednog dana (ponude ne moraju da se daju za svaki sat, a mogu i da budu identične za svaki sat), kako bi se znalo koliko će svaki generator „uneti“ snage u sistem, sa kog mesta i u kom momentu, kako bi operator prenosnog sistema mogao što preciznije da upravlja sistemom. Takođe, berze primaju ponude pre podne do određenog sata (SEEPEX ${ }^{1}$ do $10 \mathrm{~h}$ ), kada zatvaraju berzu za sutrašnji dan i na taj način ostavljaju dovoljno vremena operatoru prenosnog

1 SEEPEX - South-East Europe Power Exchange - licencirani operator za organizovano tržišne energije, formiran kao strateško partnerstvo između JP EMS i EPEX SPOT sa sedištem u Beogradu sistema da uoči i razreši eventualna zagušenja i probleme sigurnosti na mreži. Nakon toga, operator prenosnog sistema organizuje aukcije za sistemske usluge regulacije i obrtne rezerve, gde ponude iznose generatorske kompanije, a kupac je operator prenosnog sistema (generatorskim kompanijama se plaća određena cena, koja je niža od cene električne energije za držanje rezervnog kapaciteta). Bez preciznih i detaljnih informacija, operator prenosnog sistema ne bi mogao da uradi tačan proračun tokova snaga i potencijalno bi doveo do nemogućnosti realizacije ugovora sklopljenih na berzi ili direktnim trgovanjem. Iz navedenog proizilazi da je preduslov funkcionisanja tržišta električnom energijom održivi Power flow, bez povreda sigurnosti i zagušenja.

Na berzi se trgovina odvija putem centralizovane aukcije gde ponuđači unose svoje ponude (cenu i količinu), ponude se slažu naviše i na taj način kreiraju krivu ponude. Potrošači unose svoje ponude (cenu i količinu), ponude se slažu naniže i na taj način kreiraju krivu tražnje. Presek određuje ravnotežu tržišta, odnosno količinu i cenu po kojoj će se ona razmeniti. Ponude podnose licencirani učesnici, u unapred određenoj elektronskoj formi i unapred određenom vremenskom roku. Nalozi mogu biti samo sa rokom važenja i mogu se odnositi samo na jedan ugovor. Jedan nalog se odnosi na jedan ugovor. Nalozi mogu biti prosleđeni u formi 24 naloga za 24 ugovora tokom dana. Za svaki portfolio poslednji set pojedinačnih naloga je onaj koji je važeći za dan isporuke ili za TSO${ }^{2}$. Nakon provere formalne ispravnosti i primene algoritma za određivanje MPC (market clearing price) dobija se MPC koja definiše koje su ponude prošle, a koje nisu. Ponude koje su prošle sklapaju ugovore sa berzom. Obračun i poravnanje može da vrši posebna služba u okviru berze, kao što je to slučaj u Sloveniji ili posebna firma koja se bavi tim poslovima (SEEPEX je taj posao poverio European Commodity Clearing $A G)$.

\section{UPOTREBA TRŽIŠNE MOĆI NA BERZI ELEKTRIČNE ENERGIJE}

Tržišna moć predstavlja stepen kontrole koji jedna ili mali broj kompanija imaju nad odlučivanjem o ceni i proizvodnji u nekom sektoru. Najčešća mera tržišne moći je stopa koncentracije tržišta (Samuelson \& Nordhaus, 2010, str. 188), a najčešće korišćeni indeks za merenje koncentracije i konkurencije na tržištu je Herfindal-Hiršmanov indeks (HHI). Posedovanje tržišne moći nije zabranjeno, niti je kažnjivo, ali je njena zloupotreba zabrenjena. Tržišta električne energije su ranjivija od ostalih energetskih tržišta (Borenstein, 2000).

Međutim, na deregulisanim tržištima električne energije sve je više primera zloupotrebe tržišne moći. Svakako najpoznatiji primer zloupotrebe tržišne moći je kalifornijska kriza, koja je rezultirala čestim nestancima električne energije i povećanjem veleprodajnih cena 800 odsto od aprila do de2 TSO - Transmission system operator - operator prenosnog sistema 
cembra 2000. godine. Savezna Regulatorna komisija za energetiku (FERK) je utvrdila da su neke energetske kompanije, u više navrata uspele da kreiraju veštačke nestašice iako je instalisanog kapaciteta bilo znatno više od ukupnog zahteva za opterećenjem. Zbog spremnosti energetskih kompanija da svoju tržišnu moć iskoriste za manipulaciju tržištima, potrošači u Kaliforniji su od 1998. do 2000. godine platili skoro 5,5 milijardi USD više za električnu energiju, nego što bi platili da ovakve zloupotrebe nije bilo (Bose et al., 2014).

Tržišna moć se može okarakterisati kao sposobnost jednog ili više tržišnih učesnika da određuju cene i dobit u nekom dužem razdoblju. Uopšteno gledajući, smatra se da kompanija ima tržišnu moć, ukoliko ima veliki uticaj na količinu dobara kojima se trguje i na cene po kojima prodaje na tržištu. Tržišna moć ima dve komponente (Tešnjak et al., 2009):

1. horizontalna komponenta predstavlja sposobnost međusobno konkurentnih tržišnih učesnika da kreiraju cene na tržištu iznad okvira konkurentnosti (npr. zadržavanjem isporuka).

2. vertikalna komponenta predstavlja sposobnost tržišsnog učesnika da onemogući konkurentskim kompanijama pristup nužnim inputima (npr. onemogućavanje pristupa prenosnom sistemu).

Tržišna moć je povezana sa oblikom dominacije na tržištu, gde jedan dobavljač ima mogućnost da se nezavisno od konkurenata i potrošača ponaša na način koji povećava njegovu profitabilnost. Smatra se da kompanija ima tržišnu moć, kada povlačenjem kapaciteta ili povećanjem cene za obim proizvodnje koji nudi dovodi do povećanja cene na tržištu električne energije. Svaki generator bi trebalo da pošalje ponudu koja je jednaka trošku proizvodnje, a cena na berzi bi tada bila određena troškovima proizvodnje poslednje generatorske jedinice koja ulazi nakon zatvaranje berze. U tom slučaju samo poslednja jedinica ne bi generisala profit, dok bi sve ostale generatorske jedinice koje su pre nje ušle na ber$\mathrm{zu}$ generisale profit. Upravo poslednja generatorska jedinica, koja „zatvara“ berzu predstavlja rizik zloupotrebe tržišne moći na berzi i to u slučaju:

- jednog velikog proizvođača, odnosno proizvođača sa više generatorskih jedinica,

- „kartelskog“ sporazuma,

- malih generatorskih kompanija.

Elastičnost ponude i tražnje su faktori koji ukazuju da li kompanija može da zloupotrebi tržišnu moć. Ako je tražnja veoma osetljiva na cenu, odnosno ako je tražnja elastična, onda smanjenje ponude neće značajno uticati na povećanje cene, odnosno povlačenje kapaciteta neće proizvesti željeni efekat. U suprotnom, svako smanjenje neelastične tražnje dovodi do značajnog povećanja cena i opravdanosti povlačenja kapaciteta. Slično, ako je ponuda elastična, onda ostali učesnici na tržištu neće imati interesa da povećaju cenu ili povuku kapacitet, tako da svako povlačenje kapaciteta ili povećanje cene neće proizvesti željeni efekat. U suprotnom, ako je ponuda neelastična, a druge firme ne žele ili ne mogu da povećaju svoje kapacitete da zadovolje tražnju, vrlo je izvesno da će strategija povlačenja kapaciteta ili povećanja cena biti profitabilna. Na neeleastičnost ponude značajno utiče interkonektivni kapacitet. U slučajevima visoke tražnje, kada su drugi generatori na nivou svoje maksimalne proizvodnje i dodatnom proizvodnjom ne mogu da nadoknade povučenu snagu, javlja se ograničenje na strani prenosa, koje sprečava generatore iz drugih geografskih područja da odgovore na povlačenje kapaciteta. Na taj način se smanjuje broj konkurentskih generatora na tržištu.

Ako pretpostavimo da kriva rezidualne tražnje predstavlja ukupnu tražnju umanjenu za ponudu svih ostalih proizvođača, u slučaju bazne tražnje, smanjenje ponude nastalo usled povlačenja jednog generatora će lako nadoknaditi drugi proizvođači povećanjem sopstvene proizvodnje i povlačenjem kapaciteta će izazvati neznatne cenovne efekte (sl. 1).

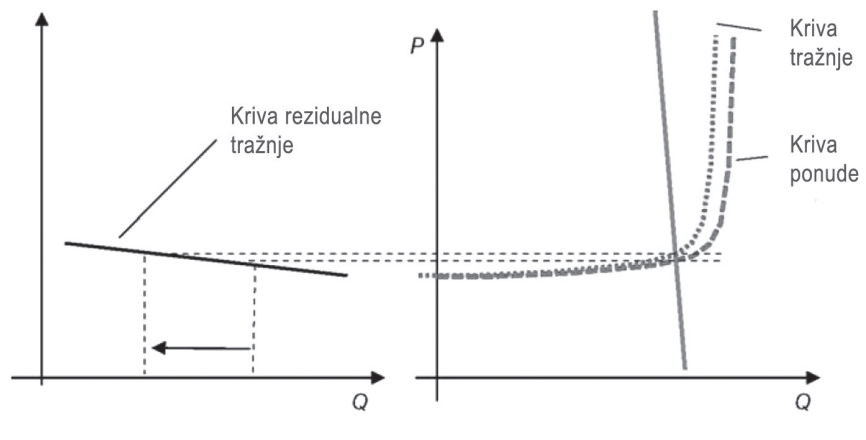

Slika 1. Promena cene u slučaju bazne tražnje Izvor: Biggar \& Hesamzadeh (2014)

U slučaju vršne tražnje situacija će biti dijametralno suprotna. Drugi proizvođači neće biti u prilici da proizvedu dodatne količine, jer su već vrlo blizu ili na nivou svog maksimalnog kapaciteta, pa će proizvođač povlačanjem kapaciteta ostvariti značajan profit, prouzrokovan koncentracijom tržišne moći koju ima na konkretnom tržištu (sl. 2).

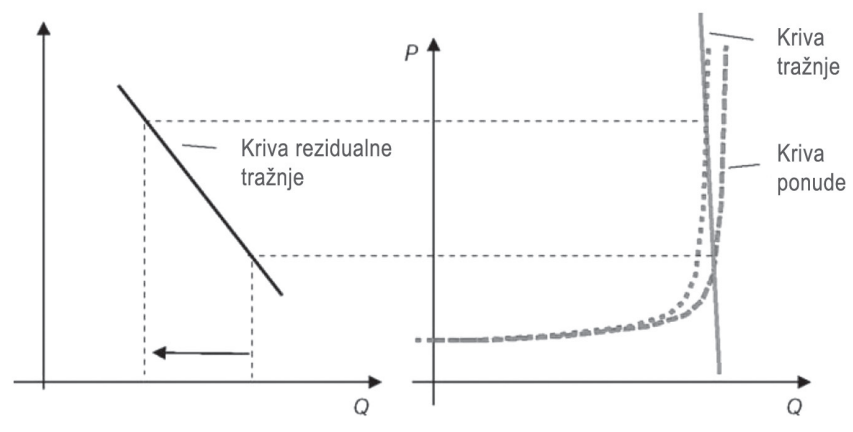

Slika 2. Promena cene u slučaju vršne tražnje Izvor: Biggar \& Hasamzadeh (2014) 
Povlačenjem određenih kapaciteta ili povećanjem cene za određeni nivo proizvodnje, generatori utiču na povećanje cene na tržištu. Ukoliko proizvođač očekuje da će njegova generatorska jedinica da „zatvori“ berzu, proizvođač koji poseduje više generatorskih jedinica može da odluči da povuče ponudu koja ne donosi profit. U tom slučaju berzu će „Zatvoriti“ generatorska jedinica koja ima veću cenu i koja će povećati cenu na berzi, a samim tim i profit generatorske kompanije koja je povukla svoju ponudu, ali i svih ostalih generatorskih kompanija čije su ponude prihvaćene. Takođe, ukoliko generatorska kompanija proceni da će zatvaranje berze na određenom nivou cene doneti mali profit, ona može neopravdano da povuče svoj najveći generator kako bi onemogućila zatvaranje berze bez zloupotrebe, odnosno da dovede do zatvaranja berze na značajno većem nivou cena. $\mathrm{Na}$ ovaj način bi generatorska kompanija angažovanjem svojih manjih generatora ostvarila značajno veći profit, nego sa generatorom koji je povukla. Visina ostvarenog profita je uslovljena nagibom krive ponude, koji mora biti dovoljno „strm“, kako bi rezultirao dovoljno visokom MCP, koja će anulirati gubitak za povučeni kapacitet. Iz navedenog proizilazi da visina ostvarenog profita predstavlja zbir :

- efekta povećanja profita nakon povlačenja kapaciteta zbog sposobnosti da podigne cenu i smanjenja troškova proizvodnje (zbog povučenog kapaciteta) i

- efekta izgubljene dobiti za povučeni kapacitet.

U tabeli 1 prikazana je profitabilnost zadržavanja kapaciteta u dva primera. Pretpostavimo da generator proizvodi 20.000 MW, ali da polovinu ukupnog kapaciteta ne nudi na tržištu, da je marginalni trošak 20 EUR i da je MCP 25 EUR/MWh. Ukoliko su ponuda i/ili tražnja neelastične, i zadržavanje kapaciteta dovodi do povećanje cena na $35 \mathrm{EUR} / \mathrm{MWh}$, generator će ostvariti povećanje profita u iznosu od 50.000 EUR. Međutim, ukoliko su ponuda i/ili tražnja elastične, zadržavanje kapaciteta će izazvati neznatno povećanje cena na $29 \mathrm{EUR} / \mathrm{MWh}$ i generator će ostvariti gubitak u visini 10.000 EUR.

\section{REGULATIVA I PRAKSA EVROPSKE UNIJE ZA SPREČAVANJE MANIPULACIJA NA TRŽIŠTU}

Kako su veleprodajna tržišta unutar Evrope veoma povezana, zloupotreba tržišta u jednoj od zemalja Evropske unije bi verovatno uticala na formiranje cena na drugim tržištima unutar Evropske unije. Uredbom (EU) br. 1227/2011 Evrop- skog parlamenta i Veća od 25. oktobra 2011. o celovitosti i transparentnosti veleprodajnog tržišta energije (engl. Regulation on wholesale energy market integrity and transparency - REMIT) uveden je jedinstveni evropski okvir na veleprodajnim tržžšima električne energije i prirodnog gasa kojim se definišu stroga pravila o zabrani davanja poverljivih informacija i manipulacija na tržištu. REMIT se odnosi na sve učesnike čije aktivnosti utiču na veleprodajna tržišta energije unutar Evropske unije. REMIT-u podležu svi učesnici na tržištu koji imaju sedište u nekoj od zemlja Evropske unije, kao i učesnici koji imaju sedište u zemljama izvan EU, ukoliko trguju ili daju naloge za trgovinu na jednom ili više tržišta unutar EU. Energetske kompanije su u obavezi da interne informacije koje se odnose na tehničke objekte za proizvodnju, isporuku, skladištenje i transport električne energije i prirodnog gasa učine dostupnim javnosti. Od 7. oktobra 2015. godine kompanije su u obavezi da Agenciji za saradnju energetskih regulatornih tela (ACER) dostavljaju informacije o standardnim transakcijama, kako ugovorima, tako i nalozima za trgovanje. U isto vreme energetski subjekti su dužni da Agenciji i nacionalnim regulatornim telima dostave informacije vezane za kapacitete i korišćenje pogona za proizvodnju, skladištenje, potrošnju ili prenos električne energije, odnosno transport prirodnog gasa, uključujući prijavljivanje planiranih ili neplaniranih prekida u radu tih postrojenja. REMIT predviđa da se adekvatno sankcionišu svi oni koji zloupotrebljavaju povlašćenu informaciju koja se odnosi na veleprodajne proizvode. Pod zloupotrebom tržišta podrazumeva se:

- korišćenje povlašćenih informacija u kupovini ili prodaji veleprodajnih energetskih proizvoda,

- dostavljanje tih informacija trećem licu ili navođenje druge osobe koja će na osnovu tih podataka sklapati poslove na tržištu,

- davanje obmanjujućih signala vezanih za ponudu, potražnju ili cene energetskih proizvoda,

- kao i sprovođenje transakcija kojima se namerno izaziva veštačko kretanje cena na veleprodajnom tržištu energije.

Međutim, definisanje zloupotrebe tržišne moći na tržištu električne energije je izazov koji zahteva precizno definisanje pojmova "konkurentni nivo" i "povećanje cene", jer može biti veoma teško razlikovati visoke konkurentne cene koje su posledica stanja na tržištu, kao i njihov porast, od cena koje su posledica zloupotrebe tržišne moći. Pored toga, da

Tabela 1. Promena profita u slučaju zadržavanja kapaciteta

\begin{tabular}{|c|c|c|c|c|c|c|c|}
\hline $\begin{array}{l}\text { ukupna } \\
\text { ponuda }\end{array}$ & $\begin{array}{l}\text { zadržani } \\
\text { kapacitet }\end{array}$ & MCP (EUR) & $\begin{array}{c}\text { MCP nakon } \\
\text { povlačenja } \\
\text { (EUR) }\end{array}$ & $\begin{array}{l}\text { ostvareni do- } \\
\text { datni prihod }\end{array}$ & $\begin{array}{l}\text { izgubljeni } \\
\text { prihod }\end{array}$ & $\begin{array}{c}\text { smanjenje } \\
\text { troškova }\end{array}$ & $\begin{array}{c}\text { promena } \\
\text { profita }\end{array}$ \\
\hline 20.000 & 10.000 & 25 & 35 & 100.000 & 250.000 & 200.000 & 50.000 \\
\hline 20.000 & 10.000 & 25 & 29 & 40.000 & 250.000 & 200.000 & -10.000 \\
\hline
\end{tabular}


bi se ustanovila tržišna moć neophodno je utvrditi da li je manipulacija bila profitabilna i namerna. Namerno kreiranje veštačke nestašice u cilju ostvarivanja dodatnog profita (zadržavanjem isporuka električne energije), nekada je praktično nemoguće razlikovati od stvarnih kvarova koji umanjuju obim proizvodnje za taj dan odnosno sat. Problem može biti i geografski nivo u kom tržišna moć može biti zloupotrebljena. Dominantan položaj može se steći na osnovu položaja kompanije na tržištu na primer:

- isporučilac električne energije sa velikim kapacitetom (pa samim tim i velikim tržišnim učešćem) ili u samo jednom segmentu ponude,

- isporučilac električne energije koji ima ograničene mogućnosti za uvoz jeftinije struje u regionu.

ACER-ov godišnji izveštaj o aktivnostima u vezi sa REMIT-om potvrđuje da utvrđivanje tržišne moći i zloupotrebe tržišta nije nimalo jednostavan zadatak. Otkako je usvojen REMIT, Agenciji je prijavljeno 10 slučajeva u 2012. godini, 12 slučajeva u 2013. godini i 33 slučaja u 2014. godini. Agencija je do kraja 2014. godine od ukupno 55 primljenih slučajeva obradila 25 , od kojih je samo kod 5 slučajeva utvrdila postojanje zloupotrebe, dok je ostalih 20 slučajeva odbačeno zbog nedostatka dokaza. Jedan od primera manipulacije količinom na evropskom tržištu je fizičko zadržavanje raspoloživih kapaciteta od strane španske kompanije "Iberdola". Manipulacija je ustanovljena od strane španskog nacionalnog regulatora zbog čega je kompaniji "Iberdola" izrečena novčana kazna od strane Nacionalne komisije za tržište i konkurenciju u Španiji u visini od 25 miliona EUR.

\section{ZAKLJUČAK}

Na osnovu svega navedenog možemo zaključiti da berze električne energije zavise od koncentracije tržišta, povezanosti proizvođača i snabdevača i interkonektivnog kapaciteta. Evropska unija je prepoznala značaj sprečavanja manipulacija na tržištu električne energije i donela mere za sprečavanje: korišćenja povlašćenih informacija; dostavljanje tih informacija trećem licu ili navođenje druge osobe da na bazi tih podataka sklapa poslove na tržištu; davanje obmanjujućih signala vezanih za ponudu; potražnju ili cene energetskih proizvoda, kao i sprovođenje transakcija kojima se namerno izaziva veštačko kretanje cena na veleprodajnom tržištu energije. Uredbom od 25. oktobra 2011. godine o celovitosti i transparentnosti veleprodajnog tržišta energije (REMIT) uveden je jedinstveni evropski okvir na veleprodajnim tržištima električne energije i prirodnog gasa kojom se definišu stroga pravila o zabrani davanja poverljivih informacija i manipulacija na tržištu.

U sprečavanju tržišnih manipulacija značajno mesto zauzima identifikacija tržišne moći i sprečavanje njene zloupotrebe. S obzirom na činjenicu da veleprodajna tržišta pružaju glavne cenovne signale koji utiču na tržišne odluke proizvođača i potrošača, kao i investicije u proizvodna postrojenja te prenosnu, odnosno distributivnu infrastrukturu, veoma je važno povećati transparentnost na veleprodajnom tržištu, smanjiti rizik od manipulacije tržištem i omogućiti formiranje adekvatnih tržišnih cena. Politike koje se koriste za smanjenje tržišne moći su: smanjenje koncentracije na tržištu, povećanje brzine reakcije tražnje na promenu cena, smanjenje zagušenja na prenosnoj mreži, povećanje prosečnog nivoa hedžinga, price caps i kontrola nadmetanja.

Razvoj tržišta električne energije od usvajanja odgovarajućeg Memoranduma o razumevanju 2002. godine u Atini, ostvario je značajan napredak, iako je praćen brojnim problemima kao što su: odsustvo konkurencije, nekvalitetna struktura za prenos energije, nedostatak regulative, razvijenih institucija i drugi (Jeremić, 2006). Imajući u vidu da se radi o mladom i nedovoljno razvijenom tržištu, ublažavanje zloupotrebe tržišne moći postaje aktuelno pitanje za različite regulatorne agencije. U cilju očuvanja sigurnosti snabdevanja, restrukturiranje tržišta električne energije dovelo je do postojanja nekoliko velikih igrača koji obezbeđuju tržišnu efikasnost. Regulatori su uglavnom nasledili strukturni nedostatak nesavršene konkurencije. U takvim okolnostima, praćenje ponašanja i postavljanje okvira za sprečavanje zloupotrebe tržišne moći jednog ili više preduzeća koja poseduju tržišnu moć je veoma kompleksan zadatak.

Postoji velika potreba da se tržišna moć sagleda iz kratkoročne i dugoročne perspektive, uzimajući u obzir ekonomsku osnovu i fizičke karakteristike prenosnih sistema. U godinama koje slede pametne mreže, koje podrazumevaju visok stepen penetracije obnovljivih izvora energije, distribuiranu proizvodnju, skladištenje energije i povećano korišćenje „demand-respond“ programa, će povećati potrebu za novim merama. Nudeći veću fleksibilnost, sve komponente pametne mreže će uticati na ponašanje kompanija na tržištu, a uzročno-posledično i na njihovu tržišnu moć.

\section{LITERATURA}

Agency for the Cooperation of Energy Regulators. (2014). ACER's Annual report on its activities under REMIT in 2013. Retrived September 15, 2016, from http://www.acer.europa. eu/Official_documents/Acts_of_the_Agency/Publication/ REMIT\%20Annual\%20Report\%202014.pdf

Biggar, D., \& Hesamzadeh, M. (2014). The Economics of Electricity Markets. Indianapolis: Wiley.

Borenstein, S. (2000). Understanding Competitive Pricing and Market Power in Wholesale Electricity Markets. The Electricity Journal, 13(6), 49-57.

Bose, S., Wu, C., Wierman, A., \& Mohsenian-Rad, H. (2014). A Unifying Market Power Measure for Deregulated Transmission-Constrained Electricity Markets. IEEE Transactions on Power Systems 50(3), 2338-2348.

Emissions - EUETS. (2016). Market manipulation under REMIT. Retrived September 15, 2016 from http://www.emissionseuets.com/market-manipulation-remit 
European Commission. (2003). Memorandum of Understanding on the Regional Electricity Market in South East Europe and its integration into European Union Internal Electricity Market. Retrived September 15, 2016, from http:// ec.europa.eu/enlargement/archives/seerecon/infrastructure/sectors/energy/documents/mou-rem-see-2003.pdf

Jeremić, Z. (2006). Energetski sektor-šansa za razvoj finansijskog tržišta u Srbiji. Ekonomski anali, 51, 61-71.
Samuelson, P.A., \& Nordhaus, W.D. (2010). Economics. New York: McGraw-Hill.

Stefanović, N. (2015). Zašto i kako regulisati berzu električne energije. Beograd: CIGRE.

Tešnjak, S., Banovac, E., \& Kuzle, I. (2009). Tržište električne energije. Zagreb: Graphis.

\section{RISKS OF MARKET POWER MISUSE IN ELECTRICITY MARKETS}

\section{Abstract:}

The research subject of this paper is the possibility of market power misuse in electricity market. The primary hypothesis is that electricity markets are supposed to function according to similar principles used in financial and commodity markets, but that they are susceptible to bigger constraints which can impair the efficient performance, as well as to higher possibilities of market position misuse by the trading participants. The main purpose of this paper is both to identify and define those potential misuses and to propose the ways in which they could be reduced like: the reduction of market concentration, the increase of the demand responsiveness to a change in price, the reduction of asphyxiation on the electrical grid, the increase of the average level of hedging and bidding control.

\section{Keywords:}

electricity markets, market power, market manipulation. 